\title{
Investigation about representations used in teaching to prevent misconceptions regarding inverse proportionality
}

\author{
Matthias R Risch
}

\begin{abstract}
Background: A major problem in teaching science is the overcoming of misconceptions. Reif found a procedure specifying a science concept. Neglect of this procedure can induce misconceptions. To find what can prevent misconceptions, students entering engineering were tested to see whether they understood easy problems of movement requiring the concept of inverse proportionality. The test comprised questions about time needed by a vehicle in both linear and diagrammatic form using different representations given to the students.
\end{abstract}

Results: Science misconceptions were investigated by comparison of the answers given to the same problem using different representations of the problem. The misconceptions demonstrated by the answers confirmed models of misconceptions such as Piaget's and Reif's. Reif found a procedural concept providing a more detailed specification of a concept, which helps to avoid imprecision, which can easily creep into verbal definition statements. This was confirmed in this study. Students' conceptual knowledge was found to be highly incorrect because of confusion with preexisting knowledge acquired in daily life resulting in scientific misconceptions. It was confirmed that imprecision easily creeps into verbal definition statements, which would be avoided by explicit specification of a concept eventually recalled by a drawing.

Conclusions: Regarding the results of this study, drawings seem to protect best from misconceptions and this does not depend on other material given to the students. In teaching science, more emphasis should be on procedures specifying concepts as outlined by Reif.

Keywords: Representation; Inverse proportionality; Misconceptions; Procedures

\section{Background}

\section{What is reported in the article}

In science education, a main problem is overcoming false preconceptions and naive beliefs. The educational and cognitive sciences have given intensive consideration to naive beliefs as well as misconceptions in physics (Bao et al. 2002; Kautz et al. 2002, 2004, 2005a,b) such as the common misconception speed proportional force rather than acceleration proportional force (Bao et al. 2002; Halloun and Hestenes 1987; McCloskey 1983; Rebello and Zollman 2004).

Misconceptions about everyday life phenomena are common. These misconceptions evolve even with simple problems by neglecting critical thought. For example,

Correspondence: matthias.risch@hs-augsburg.de

Dept. AW, University of applied science, Augsburg 86161, Germany most people say wind hits one's face more during biking than it does the back. Of course, when wind comes from one direction, it comes from the other way when you ride back; thus, the chances for both sides are equal. But, because it takes longer to ride against the wind, people feel that the wind blows in their faces more often.

The educational research about misconceptions has been on the way for quite a time. Misconceptions in the minds of students about movement like this were studied in depth by McCloskey (1983), Halloun and Hestenes (1987) and Rebello and Zollman (2004). Misconceptions in application of mathematics to physics have been studied by Reif (1987) and Resnick (1985).

Psychological viewpoints of students' difficulties in the sciences have been considered, such as concepts (Posner et al. 1982; Reif 1987; Kruger et al. 1990; Licht and Thijs 
1990), schemata (Chi et al. 1981; Mestre 1991), representations (Reif 1995; Lorenzo 2005), procedural knowledge (van Heuvelen 1991a,b), cognitive anchors (Laws 1997; Hammer 2000), concept change (Abbott et al. 2000; Bao et al. 2002) and scripts (Larkin et al. 1980; Caramazza et al. 1981).

For example, misconceptions of movement can be cued by perceptual attention focussed selectively on one direction of motion alone (Reif 1987). According to Reif, misconceptions can arise from concept interpretation relying on associated knowledge fragments having the advantage of being fast and effortless.

Surveys about overcoming student's misconceptions by using new teaching methods have been undertaken, such as the Introductory University Physics Project (IUPP; Rigden et al. 1993; diStefano 1996a,b; Coleman et al. 1998 and Hestenes 1998), the Cognitive Acceleration through Science Education (CASE) study (van Heuvelen 1991a,b; Adey 1992), the Overview, Case Study (OCS: Physics; Gautreau and Novemsky 1997) and student feedback by clicker questions (Reay et al. 2005, 2008; Ding et al. 2009; James and Willoughby 2012).

The cognitive background for emergence and overcoming of misconceptions were investigated before by Piaget in the first half of the twentieth century in his famous experiments asking children about movement of toy trains overtaking each other and disappearing in a tunnel for a while (Piaget 1998, 2000; Palmer 2007). Children form a kind of 'Gestalt' about the world they live in, these ideas were used to explain novel experiences, and Piaget called this process 'assimilation'. New experiences, which cannot be explained in this way, are in 'reconciliation', which can, however, be misleading into a misconception. The concept change, which is necessary to overcome misconceptions, is difficult for students because it requires a change from the ontological categories matter or things to processes and mental states (Chi et al. 1994). Central concepts are likely to be rejected when they have generated a class of problems which they appear to lack the capability to solve (Posner et al. 1982), such as Newton's first law (force proportional change of velocity). This law is perceived by students realising the presence of frictional forces. They feel a contradiction to everyday life experiences with overwhelming influence of frictional forces (force seems to be proportional to velocity).

Representations of problems in students may be in the form of propositions or images (Posner et al. 1982), which can prevent application of central concepts, such as here in a question about the time needed in a vehicle with the influence of wind.

In the development of knowledge, intellectual norms have to be used according to Piaget's epistemology (Palmer 2007; Piaget 2000), such as autonomy, entailment, inter-subjectivity, objectivity and universality.
- Autonomy - use of own reasoning.

- Entailment (necessary knowledge) - a necessary relation about what has to be.

- Inter-subjectivity - being in line with generally accepted axioms, which are a paradigm case of common ground between different thinkers.

- Objectivity - being justified as a true response in a valid argument.

- Universality - whether or not open to transfer under different causal conditions.

Though autonomy is a condition for reasoning, it can evoke wrong representations following naive conclusions drawn from observations, which lead to misconceptions. According to Piaget, children have a tendency to adapt new observations to old naïve beliefs and misconceptions (called assimilation by Piaget) rather than having a conceptual change to new concepts explaining the phenomenon better (called accommodation by Piaget). This behaviour is explained by the tendency of students to reconcile new observations with old misconceptions (réconciliation; Posner et al. 1982; diSessa 1993).

These Piagetian perspectives on reasoning and cognitive development guide the way to find out which representation presented to the students will avoid emergence of misconceptions. Which representation presented to the students can help to overcome misconceptions is investigated here.

Piaget is undeniably one of the greatest psychologists of the twentieth century; however, recent developments have not always confirmed his findings adding new ideas and concepts such as ecological approach to perceptual learning and development and research on embodied cognition considering for example the perception of movement of objects (Gibson and Gibson 1994; Shapiro 2010).

Misconceptions can be analysed by a model of four cognitive steps, which are based on Posner et al. (1982). This model is an application of Piaget's ideas about assimilation and reconciliation when encountering new phenomena (Posner et al. 1982; Chi et al. 1994):

1. Rejection: Rejection of observational theory. (Example: the individual observes a vehicle. The time needed is not directly observable and therefore it is rejected).

2. Avoid concern: lack of concern with experimental findings. (Example: careful observation would yield to correct information; the velocity decreases; and thus, the time increases while the vehicle faces the wind. This needs reasoning which is avoided).

3. Compartmentalization: A compartmentalization of knowledge to prevent information from conflicting with existing belief. (Example: the false explanation 
could be tested by careful observation or reasoning; however, as it is difficult, this investigation is neglected and a misconception evolves, the interpretation of speed which is put in compartments like 'speed from force').

4. Assimilation: Assimilation of new information into existing naïve concepts. (Example: in the absence of critical thought, a false explanation will become a false representation).

These four cognitive features of recognition can explain the misconceptions. Considering these four steps, it seems obvious that different representations given to the students solving a problem can protect more or less from falling into misconceptions.

Reif identifies a procedure specifying a mathematics or science concept (Reif 1987, 1995). For example, the concept 'acceleration' consists of the five major steps (which should be illustrated in a figure): (1) identify the velocity; (2) velocity at a slightly later time; (3) find the small velocity change (should be done graphically by drawing); (4) find the ratio dividing by time difference and (5) calculation with the time difference chosen progressively closer to zero, this involves a subtle limiting process. Every step should be pointed out in the teaching process. This procedural concept provides a more detailed and explicit specification of a concept and helps to avoid imprecision, which can easily creep into verbal definition statements (Reif 1987, 1995). Accordingly, drawings can be assumed to be important for the understanding of scientific concepts.

\section{Purpose of this study}

The kind of representation used in teaching, which induces or avoids misconceptions of students, is investigated in this study. College students were asked to compare the time needed to complete the round trip riding a bicycle with and without wind blowing within 2 min.

The drawing provided shows vectors representing the velocity of the wind and the velocity of the rider. The velocity of the rider, as evoked through the length of the vector, is the same in both directions. The students had been told that the velocities have to be added to obtain the same velocity relative to the air. This should not easily evoke the idea that the rider is trying to maintain the same velocity to ground in both directions; otherwise, the students should have answered "Problem not clear/ fail to answer".

The purpose of this study was further investigation on misconceptions by comparing answers to questions in linear and diagrammatic form with different figures about the same everyday problem. The answers to the question are discussed in relation to well-known theories about education as well as psychological and neuroscience insight about learning and memory (Cahill et al. 1994; Erk et al. 2003). This literature on neuroscience describing the value of emotions for perception and reasoning process informed the focus of the study on the influence of different representations given with more or less emotions involved (such as image, figure, formula, definitions). The comparison of the influence of different representations is useful to find out which material or picture can evoke misconceptions and which can prevent them.

\section{Methods \\ Participants}

One hundred forty-two students at a university of applied sciences within the first semester were allocated to eight groups according to their surnames so as to have a random distribution. Each group was shown a different picture on an overhead projector and was asked the same question about movement involving a reciprocal relation. There were four different pictures; two groups were each shown the same picture, for control reasons. An everyday life experience had been chosen because such experiences have overwhelming importance in getting students involved in physics and to increase their attendance in classes (Donnelly 1998; Mahoy and Knutton 1997).

\section{Settings}

Students participating in the study were engaged in similar kinds of engineering courses at a large public German university of applied sciences. All 142 students were at the very beginning of their studies in the first week after term began.

\section{Instrument}

The picture shown to them comprised of three parts: (a, upper part) a set of vectors with arrows, (b, middle part) a side view of two bikers moving in opposite directions and (c, lower part) a definition put in a formula.

The material given to the students to solve the problem had been reduced from reality. The drawing provided shows vectors representing the velocity of the wind and the velocity of the rider. The velocity of the rider relative to the air, as evoked through the length of the vector, is the same in both directions. The students had been told that the velocities have to be added to obtain the velocity relative to the air. This should easily evoke the idea that the rider tries to maintain the same velocity relative to the air (not to the ground) in both directions.

This instrument of dividing the picture into parts can be effective for serving the purpose of this study because the efficient part of the picture can be traced this way. 
The students were shown either the entire picture or a picture with one of the three parts (a), (b) or (c) left out (upper, middle or lower part of Figure 1) in order to find out which parts are essential to find the answer. The students were allowed help such as a calculator, a textbook, a paper and a pencil.

When they looked at these pictures, the students were asked if a cyclist needs more, less or the same time cycling with or without wind for a fixed distance and the return journey. This question had to be answered anonymously and spontaneously within $2 \mathrm{~min}$ in each group. Since this question is about the time needed, finding the answer requires application of a reciprocal relation, since time for a constant movement is distance $\mathrm{s}$ divided by speed $\mathrm{v}$. When speed is increased and altered by wind speed $v_{\mathrm{WIND}}=\Delta \mathbf{v}$, then the time $t$ comes out to be:

$$
t=\frac{s}{v+\Delta v}+\frac{s}{v-\Delta v}=\frac{2 s v}{v^{2}-\Delta v^{2}}=\frac{2 s}{v-\Delta \mathrm{v}(\Delta v / v)}>\frac{2 v}{v}
$$

Therefore, wind speed $\Delta \mathbf{v}$ does not cancel out, but the total time is increased.

The problem students had to solve is highly reduced from reality and made several tacit assumptions. That the speed of wind has to be added to or subtracted into the velocity without wind will result to the same speed relative to the air in both directions. Consequently, the rider has to apply equal force while cycling in both directions, if the bike's internal friction and tire friction are neglected. This is in agreement with the experience that many people, when cycling, try to maintain a personal biomechanical optimal number of rotations per time rather that the same ground speed.

\section{Results}

Research on students' misconceptions and movement including what it is, how and why it emerges

Students restricted to naïve belief or visual imagery (Sternberg 1985; diSessa 1993) will overlook the reciprocal relationship and guess the same time of the bicycle trip. Application of mathematical symbols or concepts will overcome naïve belief (diSessa 1993) and lead to the correct result, a longer time. Superficial interpretation of previous experience of bicycling by students can become a misconception of movement. It can be called a misconception if it is applied to another movement.

The differences between the two groups for each of the four pictures were not significant as they were well below one standard deviation $\sigma$ "sigma"; one sigma $\sigma$ is assumed here to be the square root of the number of students.

The results were tested for significance by a $\chi^{2}$-test, leaving out the students who failed to answer. The answers of the students were randomly distributed within each column of Table 1 (with one kind of picture presented), while the distribution of correct answers over the columns (with differed kinds of pictures presented)

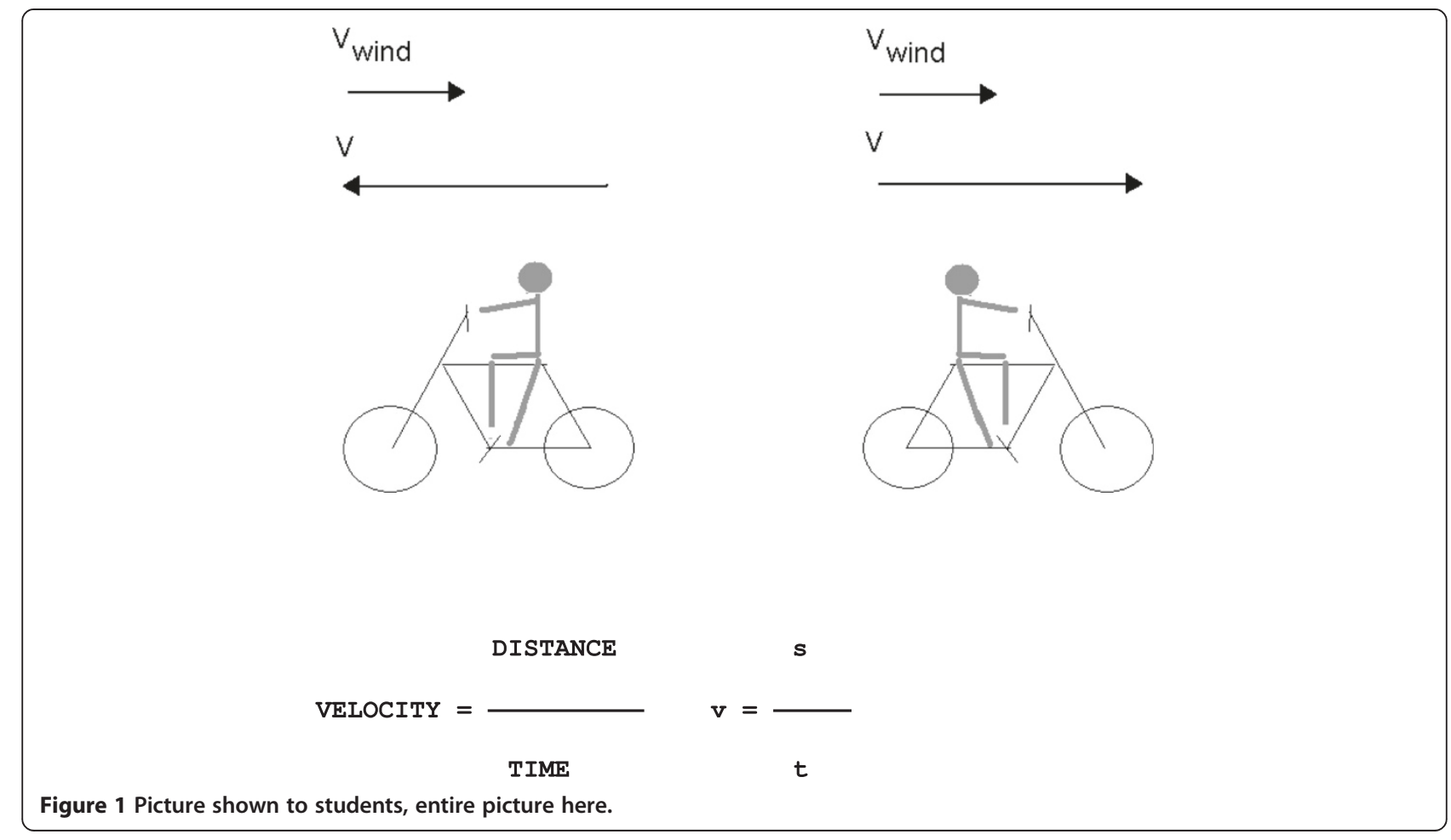


Table 1 Answers to the same question using different material (different parts omitted)

\begin{tabular}{|c|c|c|c|c|c|c|c|c|}
\hline \multirow{2}{*}{$\begin{array}{l}\text { Type of picture: which part omitted } \\
\text { Answer }\end{array}$} & \multicolumn{2}{|c|}{ Complete picture, nothing omitted } & \multicolumn{2}{|c|}{ A. Vectors omitted } & \multicolumn{2}{|c|}{ B. Drawing omitted } & \multicolumn{2}{|c|}{ C. Formula omitted } \\
\hline & Number of students & $\%$ & No. of students & $\%$ & No. of students & $\%$ & No. of students & $\%$ \\
\hline Last longer & 16 & 29 & 7 & 50 & 0 & 0 & 11 & 22 \\
\hline Last shorter & 0 & 0 & 2 & 14 & 2 & 9 & 2 & 4 \\
\hline Equal time & 28 & 51 & 5 & 36 & 19 & 83 & 29 & 58 \\
\hline Failed to answer & 11 & 20 & 0 & 0 & 2 & 9 & 8 & 16 \\
\hline Total in a group & 55 & 100 & 14 & 100 & 23 & 101 & 50 & 100 \\
\hline
\end{tabular}

was highly significant $(13.09>9.49)$. Significance of the inclusion of the drawing in the representation to find the correct answer was high.

The level of significance of the $\chi^{2}$ test has been chosen for 2 standard deviations with $\sigma=0.05,1-\sigma=0.95 ;(n=2$ degrees of freedom for each column and $n=4$ for the entire table). The Parson condition for $\chi^{2}$ test is fulfilled, less than $20 \%$ of cells smaller than 5 (Table 2).

The poor performance of students having no drawing was significant beyond two standard deviation levels $(\operatorname{sigma} \sigma)$.

Among the students who were shown the entire picture as well as students who were shown the picture either without vectors or without formula, $22 \%$ to $50 \%$ of found the right answer. In contrast, not one out of 23 students could find the correct answer when the drawing was omitted. This result is highly significant (more than two sigma), while all other deviations from one group to another were less than one or two sigma.

\section{Discussion}

Results in the view of theories about learning

These results fit well into Piagetian perspectives on reasoning and cognitive development as students relied on assimilation to naïve believe unless forced by material given to them for accommodation for a concept change.

Also, these results fit well into the theories by Posner about learning concepts and misconceptions. Concerning the first of the cognitive steps of Posner, 'rejection' of an observational theory seems to be avoided when the students see a picture of the problem. Step 2 in Posner's theory is 'Avoid concern', a lack of concern with experimental findings. The students regarding a meaningful picture seem to become aware of the experimental situation and avoid recurring to naïve belief or misconception. Careful observation of a meaningful picture can yield to correct information: the average velocity and thus indirectly the total time decrease while the vehicle faces the wind, the picture replaces real-life observation, and thus, misconceptions are avoided. Also, the picture avoids compartmentalization of knowledge: looking at the two wind directions simultaneously reminds the structure of the entire problem.

Regarding these results, drawings seem to protect best from misconceptions and this does not depend on other material given to the students.

Many students confused the concept of speed as a quotient applying a superficial thinking of time canceling out over the same distance, rather than thinking about different times needed for the two laps of the journey. This kind of 'superficiality' error is described by cognitive psychology (Reif 1987; Hammer 1996).

Students' conceptual knowledge is highly incorrect because of confusion with preexisting knowledge acquired in daily life resulting in scientific misconceptions (Reif 1987). As Reif (1987, 1995) claimed, imprecision easily creeps into verbal definition statements, which would be avoided by explicit specification of a concept eventually recalled by a drawing.

This misconception seems not to be eliminated by school instruction, because of the strength and ease of

Table 2 Significance

\begin{tabular}{|c|c|c|c|c|c|c|c|c|c|}
\hline \multirow{2}{*}{$\begin{array}{l}\text { Type of picture: which part omitted } \\
\text { Answer }\end{array}$} & \multicolumn{2}{|c|}{ Complete nothing left out } & \multicolumn{2}{|c|}{ A. Vectors omitted } & \multicolumn{2}{|c|}{ B. Drawing omitted } & \multicolumn{2}{|c|}{ C. Formula omitted } & \multirow[t]{2}{*}{ Total } \\
\hline & Number of students & $\%$ & No. of students & $\%$ & No. of students & $\%$ & No. of students & $\%$ & \\
\hline Right answer & 16 & 36 & 7 & 50 & 0 & 0 & 11 & 26 & 34 \\
\hline Wrong answer & 28 & 64 & 7 & 50 & 21 & 100 & 31 & 74 & 87 \\
\hline Total & 44 & 100 & 14 & 100 & 21 & 100 & 42 & 100 & 121 \\
\hline$x^{2}$ (column) & 1.49 & & 3.32 & & 8.21 & & 0.08 & & \\
\hline Level of significance & 5.99 & & 5.99 & & 5.99 & & 5.99 & & . \\
\hline$x^{2}$ (total) & & & & & & & & & 13.09 \\
\hline Level of significance & & & & & & & & & 9.49 \\
\hline
\end{tabular}


superficial thinking as opposed to the task of applying scientific concepts (McDermott 1991). The answers reflect a superficial way of thinking (called 'p-prim' by diSessa 1993, diSessa and Sherin 1998) avoiding the complications of dividing distance into time to get speed. As they were not shown a drawing of the problem, more students fell into this superficial thinking, confirming the theory of 'prevailing misconceptions' (McDermott 1984).

The importance of figures or drawings to find the answer to the problem is not surprising if emergence of science in antiquity is considered. In classical antiquity, science attained a very high level (Freeth et al. 2006) without use of formulae or mathematical symbols; mathematical or physical arguments or proof made use of geometric drawings rather than calculus.

\section{Conclusions}

How to avoid students' misconception based on the first part by using the correct representations

In cognitive science, there is little literature on how drawing, as a particular representation, can prevent students from misconceptions. Since there is little existing research on this topic, further related studies are necessary.

What can help students to overcome misconceptions?

The 'generic principle' teaching method by Wagenschein may help to overcome misconceptions (Heymann 2010). $\mathrm{He}$ was using derivations from general experiences and everyday perception pronounced in his ideas about teaching; for example, the concept of inertia to school students. He taught geometry to children by asking them why the moon seems to follow you when you walk along an alley, asking them about different trees. He got the answer, the further the tree...the more it follows you.... In the same way, he recommends teaching inertia: friction in sand, the vehicle will stop soon; on ice, much later and without friction, it will run forever. The generic principle is based mainly on exemplarity (Skovsmose 2010) and visual perception and supported by the observation of drawings as teaching aids, which prevent misconception.

The misconceptions and poor comprehension in sciences found in first year students lead to the conjecture that more emphasis should be on procedures specifying concepts like those outlined by Reif (1987), Purcell (1997) and Griffiths (1997). The interpretation mode of concepts suggested by Reif $(1987,1995)$ relies on knowledge defining a concept by an explicit procedure specifying how to identify or construct the concept. Scientific misconceptions can be avoided by teaching students explicit concept specification, especially concept-interpretation procedures (Reif 1987).

This conclusion is strengthened by the connection found between misconceptions and the error made avoiding the change from the ontological categories matter or things to processes and mental states (Chi et al. 1994). Student feedback by voting machines can ease concept change by students (Reay et al. 2005, 2008; Ding et al. 2009).

Since misconceptions are seemingly founded on false preconceptions, more emphasis in science teaching should be on hands-on experiments, blackboard drawings without formulas and concept-oriented teaching in sciences. This might ease the problems found, as has been concluded by diStefano (1996a,b) and Gautreau and Novemsky (1997). One single experiment can change the situation and induce concept change (Abbott et al. 2000; Bao et al. 2002).

Involving emotional events in the process of teaching improves memory and eases overcoming misconceptions (Cahill et al. 1994). Therefore, suspense stories like "How Galileo overcame superstitions" raise emotions improving memory and attendance thus easing concept change, according to results of neurological research (Erk et al. 2003). This memory improvement is confirmed by research on perception of movement (Gibson and Gibson 1994; Shapiro 2010). When the question was answered by students, fewer misconceptions showed up when the question was described by a picture, which can raise emotions as when the question was put in a linear form.

\section{Competing interests}

The author declares that he has no competing interests.

Received: 14 November 2013 Accepted: 1 April 2014

Published: 27 August 2014

\section{References}

Abbott, DE, Saul, JM, Parker, GW, \& Bleichner, RJ. (2000). Can one lab make the difference? Physics education research. American Journal of Physics Suppl, 68(7), 560-561.

Adey, P. (1992). The CASE results: implications for science teaching. International Journal of Science Education, 14(2), 137-146.

Bao, L, Hogg, K, \& Zollman, D. (2002). Model analysis of fine structures of student models: An example with Newton's third law. American Journal of Physics, 70, 766-778.

Cahill, L, Prins, B, Weber, M, \& McGaugh, JL. (1994). Beta-adrenergic activation and memory for emotional events. Nature, 371, 702-704

Caramazza, A, McCloskey, M, \& Green, B. (1981). Naive beliefs in sophisticated subjects: misconceptions about trajectories of objects. Cognition, 9, 117-123.

Chi, MTH, Feltovich, PJ, \& Glaser, R. (1981). Categorisation and representation of physics problems by experts and novices. Cognitive Science, 5, 121-152.

Chi, MTH, Slotta, JD, \& DeLeeuw, N. (1994). From things to process: a theory of conceptual change for learning science concepts. Learn. Instruction, 4(1), 27-43.

Coleman, LA, Holcomb, DF, \& Ridgen, JS. (1998). The Introductory University Physics Project 1987-1995: What is accomplished? American Journal of Physics, 66, 124.

Ding, L, Reay, NW, Lee, A, \& Bao, L. (2009). Are we asking the right questions? Validating clicker question sequences by student interviews. American Journal of Physics, 77(7), 643-650

diSessa, AA. (1993). Towards an epistemology of physics. Cognition and Instruction, 10(2-3), 105-225.

diSessa, AA, \& Sherin, BL. (1998). What changes in conceptual change? International Journal of Science Education, 20(10), 1155-1191.

diStefano, R. (1996a). Preliminary IUPP results: student reactions to in - class demonstrations and to the presentation of coherent themes. American Journal of Physics, 64(1), 58-68

diStefano, R. (1996b). The IUPP evaluation: what we are trying to learn and how we were trying to learn it. American Journal of Physics, 64(1), 49-57. 
Donnelly, JF. (1998). The place of the laboratory in secondary science teaching. International Journal of Science Education, 20(5), 585-596.

Erk, S, Kiefer, M, Grothe, J, Wunderlich, AP, Spitzer, M, \& Walter, H. (2003). Emotional context modulates subsequent memory effect. Neuroimage, 18, 439-447.

Freeth, T, Bitsakis, Y, Moussas, X, Seiradakis, JH, Tselikas, A, Mangou, H, Zafeiropoulou, M, Hadland, R, Bate, D, Ramsay, A, Allen, M, Crawley, A, Hockley, P, Malzbender, T, Gelb, D, Ambrisco, W, \& Edmunds, MG. (2006). Decoding the ancient Greek astronomical calculator known as the Antikythera Mechanism. Nature, 444(30), 587-591.

Gautreau, R, \& Novemsky, L. (1997). Concepts first - a small group approach to physics learning. American Journal of Physics, 65(5), 418-428.

Gibson, JJ, \& Gibson, EJ. (1994). Continuous perspective transformations and the perception of rigid motion. In EJ Gibson (Ed.), An Odyssey in Learning and Perception (pp. 247-262). Cambridge: Bradford MIT Press.

Griffiths, DJ. (1997). Millican Lecture 1997: Is there a text in this class? American Journal of Physics, 65(12), 1141-1143.

Halloun, IA, \& Hestenes, D. (1987). Modelling instruction in mechanics. American Journal of Physics, 55(5), 455-462.

Hammer, D. (1996). More than misconceptions: multiple perspectives on studen knowledge and reasoning, and an appropriate role for education research. American Journal of Physics, 64(10), 1316-1325.

Hammer, D. (2000). Student resources for learning introductory physics. American Journal of Physics, 68(Su), 52-59.

Hestenes, D. (1998). Who needs physics education research? American Journal of Physics, 66, 465

Heymann, HW. (2010). Why teach mathematics?: A focus on general education. In Mathematics Education Library (pp. 180-186, 235-239). Dordrecht, Netherlands: Kluwer Acade. Publ. - Springer.

James, MC, \& Willoughby, S. (2012). Listening to student conversations during clicker questions: what you have not heard might surprise you. American Journal of Physics, 80, 123-132.

Kautz, CH, Loverude, ME, \& Heron, PRL. (2002). Student understanding of the first law of thermodynamics: relating work to the adiabatic compression of an ideal gas. American Journal of Physics, 70(2), 137-148.

Kautz, CH, Flores, S, \& Kamin, SE. (2004). Student use of vectors in introductory mechanics. American Journal of Physics, 72(4), 460-468.

Kautz, CH, Heron, PRL, Loverude, ME, \& McDermott, LC. (2005a). Student understanding of the ideal gas law, part I: a macroscopic perspective. American Journal of Physics, 73(11), 1055-1063.

Kautz, CH, Heron, PRL, Shaffer, PS, \& McDermott, LC. (2005b). Student understanding of the ideal gas law, part II: a microscopic perspective. American Journal of Physics, 73(11), 1064-1071.

Kruger, CJ, Summers, MK, \& Palacio, DJ. (1990). An investigation of some English primary school teachers' understanding of the concepts force and gravity. British Educational Research Journal, 16, 383-397.

Larkin, J, McDermott, J, Simon, DP, \& Simon, HA. (1980). Expert and novice performance in solving physics problems. Science, 208, 1335-1342.

Laws, PW. (1997). Millican Lecture 1996: Promoting active learning based on physics education research in introductory physics courses. American Journal of Physics, 65(1), 14-21.

Licht, P, \& Thijs, GD. (1990). Method to trace coherence and persistence of preconceptions. International Journal of Science Education, 12, 403-416.

Lorenzo, M. (2005). The development, implementation and evaluation of a problem solving heuristic, Int. Internation Journal of Science and Mathematics Education, 3, 33-58.

Mahoy, KA, \& Knutton, S. (1997). Using out-of-school experience in science lessons: reality or rhetoric? International Journal of Science Education, 19(7), 849-867.

McCloskey, M. (1983). Intuitive physics. Scientific American, 248(4), 122-130

McDermott, LC. (1984). Research on conceptual understanding in mechanics. Physics Today, 7, 24-32.

McDermott, LC. (1991). Millican Lecture: What we teach and what is learned- closing the gap. American Journal of Physics, 59(4), 301-315.

Mestre, JP. (1991). Learning and instruction in pre-college physical science. Physics Today, 9, 56-62.

Palmer, JA. (2007). Fifty Modern Thinkers on Education from Piaget to Present (7th ed., pp. 39-41). New York: Routledge.

Piaget, J. (1998). De la pédagogie (pp. 99-175). Paris: Odile Jakob.

Piaget, J. (2000). la psychologie de I' Intelligence ((chapters IV and V), Paris: Armand Colin. Translation: Cotta, (1998) 10th ed., pp. 99-175). Stuttgart: Cotta.
Posner, GJ, Strike, KA, Hewson, PW, \& Gertzog, WA. (1982). Accommodation of a scientific conception: toward a theory of conceptual change. Science Education, 66(2), 211-227.

Purcell, EM. (1997). The new practical physics. American Journal of Physics, 65(8), 692-697.

Reay, NW, Bao, L, Li, P, Warnakulasooriya, R, \& Baugh, G. (2005). Toward the effective use of voting machines in physics lectures. American Journal of Physics, 73(6), 554-558.

Reay, NW, Li, P, \& Bao, L. (2008). Testing a new voting machine question methodology. American Journal of Physics, 76(2), 171-178.

Rebello, NS, \& Zollman, DA. (2004). The effect of distracters on student performance on the force concept inventory. American Journal of Physics, $72(1), 116-125$

Reif, F. (1987). Interpretation of scientific or mathematical concepts: cognitive issues and instructional implications. Cognitive Science, 11, 395-416.

Reif, F. (1995). Understanding and teaching important scientific thought processes. American Journal of Physics, 63(1), 17-32.

Resnick, LB. (1985). Mathematics and science learning: a new conception. Science, $220,477-478$

Rigden, JS, Holcomb, DF, \& DiStefano, R. (1993). The introductory university physics project. Physics Today Ap, 32-37.

Shapiro, L. (2010). Embodied Cognition (pp. 29-30). New York: Routledge. London: Taylor \& Francis.

Skovsmose, O. (2010). Thematic approach in mathematics education: exemplarity. In Towards a Philosophy of Critical Mathematics Education (Mathematics Education Library) (pp. 73-78). Dordrecht, Netherlands: Kluwer Academic Publishers - Springer.

Sternberg, RA. (1985). Human intelligence: the model is the message. Science, 230, 1111-1118.

van Heuvelen, A. (1991a). Learning to think like a physicist: a review of researchbased instructional strategies. American Journal of Physics, 59(10), 891-897.

van Heuvelen, A. (1991b). Overview, CASE study physics. American Journal of Physics, 59(10), 898-907.

doi:10.1186/2196-7822-1-4

Cite this article as: Risch: Investigation about representations used in teaching to prevent misconceptions regarding inverse proportionality. International Journal of STEM Education 2014 1:4.

\section{Submit your manuscript to a SpringerOpen ${ }^{\odot}$ journal and benefit from:}

- Convenient online submission

- Rigorous peer review

- Immediate publication on acceptance

- Open access: articles freely available online

- High visibility within the field

- Retaining the copyright to your article

Submit your next manuscript at $\gg$ springeropen.com 